The Journal of

Thoracic and Cardiovascular Surgery

Vol 122, No. 2, August 2001

\title{
Statistics for the rest of us
}

Andrew S. Wechsler, MD

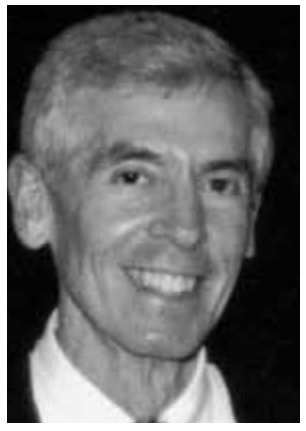

See related article on page 216.
From the Department of Cardiothoracic Surgery, MCP Hahnemann University, Philadelphia, $\mathrm{Pa}$.

Received for publication May 23, 2001; accepted for publication May 23, 2001.

Address for reprints: Andrew S. Wechsler, MD, MCP Hahnemann University, 245 North 15th St, MS 496, Philadelphia, PA 19102-1192 (E-mail: jtcvs@ drexel.edu).

J Thorac Cardiovasc Surg 2001;122:207-8

Copyright (C) 2001 by The American Association for Thoracic Surgery

0022-5223/2001 $\$ 35.00+0 \quad \mathbf{1 2 / 1 / 1 1 7 5 3 4}$

doi:10.1067/mtc.2001.117534

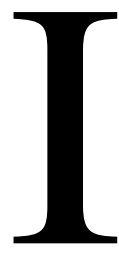

n every issue of the Journal, I am sure our readers recognize the intense statistical scrutiny to which manuscripts are subjected. Trust me, authors are even more aware of the rigor with which statistical analyses are assessed. In this regard, the Journal exerts a protector role for our readers. We are committed to the notion that, if you read it in the Journal, you can "take it to the bank." We accomplish that through no genius in the editorial office but rather through access to the best statistical reviewers for medical work that are available.

I remember a book I once read, Lies, Damn Lies, and Statistics: The Manipulation of Public Opinion in America, by Michael Wheeler. To me, the more complex the statistics become, the more concerned I become about how to interpret the message. Contemporary statistics is a powerful tool that extracts relevant data from a morass of information that may conceal as well as reveal important truths. I am concerned that most of our readers do not have an adequate understanding of contemporary statistical methods and are overly reliant on us to filter information that we present in the Journal. Much of this is the consequence of the evolution of knowledge. We read articles on gene transfer of coding elements for specific proteins that affect our everyday practice. Yet, how many of us are qualified to understand adequately the nuances of molecular biology?

I think you trust us to be certain that, before we print an article, we have made sure that appropriate methods have been used by the authors that allow them to present to you important conclusions drawn from their work. You read articles about the durability of mitral valve repair or the safety of off-pump coronary artery bypass grafting or cerebral protection during aortic dissection repairs and use this information to inform your patients, choose operations, and teach others. The fundamental core for the validity of each and every one of these divergent articles is the extent to which the statistics employed adequately revealed the "truth" of the presentation.

I would be more comfortable if I knew that you, our readers, possessed the tools to challenge, on a regular basis, the conclusions presented to you. I argue that understanding the statistics is the common element necessary to understanding the validity of any study, be it a case presentation, a clinical series, an adventure in molecular biology, or the application of a new device.

Over the next few months, we are going to try to help with that process. At the very least, we want to be certain that you are comfortable with the terminology used and have a broad understanding of why certain statistical processes are used. We will begin with a brief discussion by Drs Gary Grunkemeier and YingXing Wu that contrasts actuarial analysis with actual event analysis. The following month, Dr Eugene Blackstone reviews briefly some of the analysis modalities in use to prepare the way for a two-part statistical "clinical-pathologic conference." Our case is a manuscript written by Dr Tom Rice and several of his colleagues from The 
Cleveland Clinic. In that issue of the Journal and in the following issue, Dr Blackstone and Dr Rice will dissect the statistical methods used to create the manuscript. This approach will serve as a paradigm that can be applied to other articles in our specialty. We are going to introduce, define, and use some of the terms of contemporary statistics that are most relevant. A partial list of terms introduced is provided at the end of this paragraph. If you are unfamiliar with any or all of them, I urge you to expend the necessary cerebral energy to understand fully the articles. Your patients will be the ultimate beneficiaries of your efforts. The terms that we dissect include categorical and continuous variables, logistic regression analysis, parameters, parametric and nonparametric data sets, Kaplan-Meier survival curves, actual survival curves, hazard functions, parsimony, coefficients, log-rank testing, Cox proportional hazards modeling, bootstrapping, univariable analysis, and multivariable analysis. If you need to see a few old friends, let me also throw in $\chi^{2}$ testing, standard deviation, and standard error of the mean.

The issue after the clinical-pathologic conference presentations will contain an article by Dr Blackstone about the evolving and important technique of propensity scoring to facilitate patient matching in retrospective analyses.

The correct technical execution of statistical methods is a skill set reserved for a select few. However, understanding the nature of statistics and the correctness of their application is a responsibility that cannot be abrogated. I hope these articles will also spark some lively debate and will encourage clinician scientists to voice their thoughts about statistical applications and their role in the contemporary interpretation of clinical and basic science data. 